\title{
Innovation Clusters and Public Policy-The Case of a Research-Driven Cluster in Germany
}

\author{
Oliver Mauroner \\ Innovation and Creativity Management, Bauhaus-University Weimar, Weimar, Germany \\ Email: oliver.mauroner@uni-weimar.de
}

Received 20 November 2015; accepted 12 December 2015; published 15 December 2015

Copyright (C 2015 by author and Scientific Research Publishing Inc.

This work is licensed under the Creative Commons Attribution International License (CC BY). http://creativecommons.org/licenses/by/4.0/

(c) (j) Open Access

\begin{abstract}
Regional innovation clusters are spatial concentrations of interconnected firms, suppliers, service providers, state institutions, and research organisation in a particular field of innovation. The stimulation and support of clusters are important agendas for governments and other public actors. Cluster development initiatives are actually an important direction in economic policy, building on earlier efforts in macroeconomic stabilization, privatisation, and market opening, and reducing the costs of doing business. The purpose of this paper is to look on a specific type of innovative clusters in Germany, which are supported by the Fraunhofer Society, one of the leading, partly public-funded organisations for application-oriented research in Europe. Based on an overview over current issues in cluster literature-beginning with Porter 1990 to the point of actual global-value-chain-approach and the concept of knowledge hubs-the particular cluster approach of the German Fraunhofer Society is classified with regard to the academic literature. Fraunhofer clusters are, in the first instance, project clusters compared to simple communication networks. The case study presented in this paper is a valid example for a long-term and well-established industry cluster, which actually opens out in a project-oriented cluster approach. Finally, it is possible to draw practical implications for policy makers and industry regarding the support of regional innovation clusters.
\end{abstract}

\section{Keywords}

Innovation Cluster, Regional Cluster, Public Policy, Fraunhofer Innovation Cluster, Jena Optics Cluster

\section{Introduction}

The wide interest in regional innovation clusters from policy makers and researchers reflects the fact that

How to cite this paper: Mauroner, O. (2015) Innovation Clusters and Public Policy-The Case of a Research-Driven Cluster in Germany. American Journal of Industrial and Business Management, 5, 736-747.

http://dx.doi.org/10.4236/ajibm.2015.512072 
place-specific, local and regional factors have been preserved and actually increased their significance in economic development [1]-[3]. The growing significance of clusters and place-related activities is attended by the crisis in Fordism by the end of the 1970s and the emergence of new forms of production. The change from mass production of standardised articles towards small batch and flexible production flows of sophisticated goods is still going on, as well as the change from hierarchical firms towards networks of firms and open innovation approaches.

In the post-war period of mass production, innovation widely took place within large companies as the result of a more or less linear process [4]. This linear innovation model describes the innovation process as an operation sequence from research through development to production and finally marketing [5]. The process itself is characterised by specialisation and separation. Consequently, research and development are separated from production with constrained knowledge exchange between them. Separation is also reflected in the spatial division of labour. Large firms typically locate most of their research and development near universities and other research institutions, and with good access to highly qualified labour. Production of standardised commodities is typically located in branch plants in outlying areas. So the production plants are marginally involved in innovative activity, and have little knowledge exchange with other local firms. Thus, they do not stimulate the formation of regionally concentrated firm clusters.

The transition to post-Fordism is attended by changes in the innovation process, in particular by a more important role for place in economic development and innovation [6]. This reflects changes in the location pattern of industry; especially the appearance of networks and clusters. Now innovations take place as incremental and interactive learning between divisions, firms and their external environment. The economy is conceptualised as learning economy and the environment is conceptualised in terms of national, regional or local systems of innovation [7]. An increasing competition, shorter product cycles and more uncertain and fluctuating markets have made knowledge and learning more important factors in the economy.

Firms now may carry through frequent, incremental innovations to survive which increase the importance of tacit, non research-and-development-based knowledge, while straight $\mathrm{R} \& \mathrm{D}$-competence has become less important compared to its position within the linear model of innovation. This type of tacit knowledge includes skills built up through long experience in a specific sector. Therefore, it is related to people and transferred through informal learning in local communities.

Innovations call for close, confident and long-lasting cooperation between firms and other institutions. This kind of cooperation about innovation must often be face-to-face and can best take place when the relevant players agglomerate spatially, whereby meetings can be arranged at short notice when firms are located in the same area. This is stimulating the formation of regional networks and clusters. Moreover, cooperation about innovation requires loyalty, and mutual trust and understanding, which not only is place-related but also takes time to develop [7]. These preconditions for cooperative innovation—mutual trust and understanding, actor-related certainty - are encouraged when actors know the same formal and informal rules and routines of cooperation. Rules and conventions are place-specific interdependencies between actors since they are often the result of a long historical process in a region [8]. According to Maillat [9], rules and conventions as formal and informal territorial factors are able to set up territorial development of innovation. Altogether, the increasing importance of regional clusters is regarded as a visible sign of wider changes towards a knowledge-driven economy or even a completely new form of knowledge society.

The cluster concept has been of great interest to policy-makers at all levels, from international authorities, national governments in different and often very dissimilar countries (e.g. USA, Germany, Singapore, Japan, India, Mexico), as well as regional and local actors. All have been intent upon finding a form of industrial policy that focuses on the stimulation and promotion of successful, competitive economies to spur cluster development. St John and Pouder [10] noted that "virtually every state in the US has a cluster development strategy as part of its economic development plan”. It can be confirmed that public authorities as well as public funded actors such as universities and research institutes have a strong interest in stimulating and bringing forward regional cluster structures. Policy dilemmas may arise when there is a desire to develop similar clusters in different regions or competitive clusters undermining the already existing ones. Policy makers and authorities need to deal with different fundamental questions in order to consider historical background, existing local strengths, current structures of regional networks, breadth and depth of cooperative relationships, as well as technology and market related issues.

The present paper represents an in-depth study of a well-established innovation cluster in Germany where a 
critical mass of local actors is convened. The paper furthermore focuses on an institutional approach of cluster support, which is to provide project-related instruments for the further development of existing strengths and regional excellence. The paper finally elaborates on the meaning of long-term cooperation, common trust, mutual understanding, actor-related certainty, and a shared vision within an innovation cluster by creating an invisible tie across the different cluster actors.

\section{Innovation Clusters and Cluster Development in Theory and Practice}

\subsection{Regional Clusters and Cluster Theory Formation}

Clusters are spatial concentrations of interconnected firms, suppliers, service providers, and associated institutions-like universities or other research institutes-in a particular field that are present in a specific region. According to Michael E. Porter [11] clusters arise because they increase the productivity with which companies can compete. The development and upgrading of clusters is an important agenda for governments, companies, and other institutions. Cluster development initiatives are actually an important direction in economic policy, building on earlier efforts in macroeconomic stabilization, privatisation, and market opening, and reducing the costs of doing business.

In the early 20th century economists have investigated the emergence and sustainability of agglomerations - referred to as industrial districts - in order to explain the microeconomic benefits of industrial collocation, for example technological spillovers [12]. Thus, prosperous districts are made up not only of physical flows of inputs and outputs, but also involve the exchange of business information, knowledge, and technological expertise, both in traded and untraded forms.

This work had been mostly forgotten until Krugman [13] and Porter [14] brought it back to the academic and political discussion. Following Porter [15] the success of regional clusters is based on its competitive advantage. Clusters are driven by competition in three ways: it increases the productivity of single firms, it accelerates the innovation process, and it stimulates the process of new venture formations increasing the overall strength of the cluster. Therefore, it is essential to understand how and why clusters develop their competitive advantage compared to other regions. With support of his “competitive diamond” Porter [15] illustrates how a nation (or a region) achieves a competitive advantage. Thus, four components are responsible for the competitive advantage of an industry: factor conditions, demand conditions, related and supporting industries, and firm strategy, structure, and rivalry. These components are interacting with each other and finally creating the competitive advantage.

Many Authors refined the regionalised diamond concept to explain the emergence and facilitation of economically advantageous knowledge in innovation systems. Recent works perceive clusters as integrating hubs in global value chains coming to transnational oriented concepts like the global-value-chain-approach [16] or multidimensional cluster conceptions [17]. Recently many authors [18] [19] consider those relations, which exist between cluster firms and actors outside the cluster as they have been found to notably influence their dynamics. Bathelt, Malmberg and Maskell [20] state that "particularly successful clusters are the ones that are able to build and maintain a variety of channels for low-cost exchange of knowledge with relevant hot-spots around the globe”. Evers [21] explains why clustering takes place despite a rapid growth of communication technology and presents the concept of knowledge hubs, which are nodes in networks of knowledge sharing. As meeting points of knowledge communities, knowledge hubs are responsible for the generation of knowledge and the transfer of knowledge to sites of application.

\subsection{Efficiency, Knowledge and Networks: Different Strands in Cluster Literature}

The growing academic interest in the factors that support high performing clusters has emerged scholars in different fields-geography, economy, and management-which consider the social and economic processes that drive firm agglomeration [1]. Basically there are three different but partly overlapping strands in cluster literature.

From the first point of view high performing clusters are supported by the economic efficiencies they confer on constituent firms, including increased specialization, reduced transaction costs and enhanced reputation. Proximity allows firms to take advantage of scale and positive external effects such as a plenitude of highly skilled labour, specialized subcontractors and rapid flows of knowledge and information [22]. Moreover, spatial proximity is thought to facilitate the profitable de-integration of value chains by allowing greater specialization of inputs and outputs, leading to improved efficiency and shorter time to market [23]. 
Another strand in cluster literature draws on the nature of the relationships that emerge across organisational boundaries, and considers that cluster performance is rooted in the social networks that bind co-located firms [24]. From this point of view, two network characteristics are important for high performing clusters [25]: strong network ties, which facilitate the transfer and assimilation of knowledge within clusters; and openness to new network, which are able to provide access to new knowledge and new ways of doing business. Implicit in this standpoint is the assumption that successful clusters exhibit these network characteristics regardless of external circumstances or market-related factors. Therefore the social network perspective has been used to explain the success of many regions and clusters around the world, the most notable of which is Silicon Valley [26].

A third strand in the literature focuses on the distinctive dynamics of knowledge transfer among co-located companies and actors as the main determinant of cluster performance [27]. The key advantages of clustering processes are to be found in knowledge creation and learning within geographical regions. Specifically, through shared conditions and experiences, clusters are able to increase the speed and ease with which members can identify, access and transfer valuable knowledge. This type of-tacit-knowledge is difficult to codify and may be exchanged more successfully through frequent interpersonal contacts that are facilitated by regional proximity [28].

\subsection{Maintaining the Integrity of the Specifications}

Clusters can be characterised along a series of dimensions, including geographic scope, breadth, depth, and others such as activity base, growth potential, competitive position, and innovative capacity.

First of all the geographic scope of a cluster refers to the territorial extent of the companies, customers, suppliers, supporters, research institutes, and other institutions that are embedded in the ongoing relationships and interdependent activities that characterize the cluster. The geographic span of a cluster may range from an area within a city to areas encompassing much of a nation [29]. Another dimension is the breadth of a cluster, which refers to the range of horizontally related industries within the cluster such as industries related by common technologies, end users, and distribution channels. Broad clusters provide a variety of products in closely related industries while narrow clusters consist of one of a few industries and their supply chains. The depth of clusters refers to range of vertically related industries within the cluster. Shallow clusters are those that rely principally on inputs, components, equipment, technology, and support services from outside the region, whereas deep clusters are those in which a region does contain an industry more or less complete supply chains. Another dimension is the activity base of a cluster which involves the number and nature of the activities in the value chain that are performed within the region. In activity-rich clusters, many of the critical activities in the value chain are performed locally. Thus, firms in activity-rich clusters tend to conduct the core strategy-setting, product or service development, and marketing strategy within the region. Tracey, Heide and Bell [8] described the Scottish whisky cluster, which has evolved to a consolidated structure where a few multinational companies (responsible for $80 \%$ of production) have reshaped the supply chain to one characterized by central decision making. As a result, smaller firms are constrained to implement strategic changes such as investing in just-in-time techniques or more efficient production plants in order to adapt to the progressively centralized character of the cluster [30].

In his book The Competitive Advantages of Nations' Porter [14] popularized the concept of industrial clusters and examines two basic types of clusters: vertical and horizontal clusters. Vertical clusters are made up of industries that are linked through buyer-seller relationships; while horizontal clusters include industries which might share a common market for the products, use a common technology, labour force skills and similar resources. The industry clusters that drive regional economies today are very different from the old ones that were mainly rooted in manufacturing [31]. The new economy is all about innovation, flexibility, and networks. Production is becoming more decentralised and sub-contracting is omnipresent.

Ingstrup and Damgaard [3] underline that clusters normally develop in accordance with a life cycle where actors from different sectors - public and private-are engaged and where one or more facilitators are coordinating the cluster process. Prior to this Enright [29] proposed a cluster typology by the level of activity and self-realization, and differentiates between potential, latent, and working clusters as well as policy driven clusters and wishful thinking clusters (Table 1). Using Enright's terminology, a working cluster, such as the Silicon Valley in the United States is an "agglomeration of connected companies that are aware of their interdependence, value it, act on it, and collectively operate as a system to produce more than the sum of their individual parts" [32]. Other cluster life cycle concepts [33] focus on the fundamental dynamics behind the developmental process 
Table 1. Cluster typology by stage development (Enright, 2003).

\begin{tabular}{|c|c|}
\hline Cluster type & Cluster characteristics \\
\hline Working cluster & $\begin{array}{l}\text { A critical mass of local knowledge, personnel, and resources create agglomeration } \\
\text { economies that are used by firms to their advantage in competing with } \\
\text { those outside the cluster. Often attract resources from other locations }\end{array}$ \\
\hline Latent cluster & $\begin{array}{l}\text { Clusters with a high number of firms but with a low level of interaction due to } \\
\text { the lack of trust and knowledge, low cooperation, and high transaction costs }\end{array}$ \\
\hline Potential cluster & $\begin{array}{l}\text { Some elements for the development of successful clusters are already } \\
\text { in place but need to be deepened and broadened. }\end{array}$ \\
\hline Policy driven cluster/Wishful thinking cluster & $\begin{array}{l}\text { Chosen by government to support but which lack a critical mass } \\
\text { of firms or favourable conditions for organic development; Sometimes more } \\
\text { "wishful thinking” than real cluster opportunities }\end{array}$ \\
\hline
\end{tabular}

and the knowledge transfer within clusters, and therefore include the stages of emergence, growth, sustainment and decline.

\subsection{The Role of Research Institutions within Clusters}

Public research institutions can play a vital role within clusters by facilitating knowledge exchange, trusting relationships and diffusing information among cluster members that serve as resources to one another. According to Eisingerich, Bell and Tracey [1] public research institutions can help the cluster members to avoid collective fatigue and inertia as well as excessive competition.

Public research centers as well as universities provide more open channels, spilling new knowledge across proximate cluster actors much more readily than industrial or commercial organizations [34]. Public research institutions, therefore, can play an important role in facilitating the openness needed to expand new knowledge and develop innovation.

Strong relationships between firms and research institutes or universities characterize regional clusters. For example, the head of R \& D of an Austrian biotechnology company in the Vienna cluster stated: "We share laboratory equipment and know-how with local research institutes. Without the guaranteed access to local research facilities, we would not be able to progress as quickly as we are" [1]. As cluster player's trust increases, continued exchange creates new opportunities for cooperation and the effective employment of a greater variety of complementary, strategic resources. In short, public research centres can influence the configuration of networks of clustered firms.

\section{The Fraunhofer Approach of Regional Innovations Clusters in Germany}

Fraunhofer Society is a fixed element in the German research landscape with the purpose to transform scientific findings into useful innovations. Fraunhofer Society was established in 1949 and is now the largest provider of application-oriented research in Europe. The 80 research units, including 66 institutes, at different locations in Germany undertake applied research of direct utility to private and public enterprise. The total annual research budget is 2.1 billion US\$, of which more than $85 \%$ is generated through contract research with industry and from publicly financed research projects.

Fraunhofer research institutes in Germany are mostly located in well-developed areas with industrial firms, universities and higher education institutes as well as other research partners nearby. Therefore Fraunhofer Society promotes innovation clusters to intensify the existing forms of networking. Superior aim of all Fraunhofer Innovation Clusters is to strengthen the competitive position of national research and to improve national innovation culture by more efficiently tapping existing potentials. The clusters on one hand create collaboration, and on the other hand stimulate competition in the market, which at the end of the day benefit everyone involved. Therefore, innovation clusters provide impetus for further development of regional centres of excellence, and primarily serve as instruments to develop existing strengths. Up to now 22 innovation clusters have been founded and already generated numerous innovative products. The purpose is to pool the strengths of a region and activate them to solve demanding tasks, such as personal health or secure identity for example. In addition to companies and universities, the networks include local non-university research institutes that can make important contributions in relevant thematic areas in order to provide impetus for the further development of re- 
gional centres of excellence, and support the regions' skills and expertise. The new infrastructures act as stimuli to ensure the position of domestic industry in global competition.

Fraunhofer Innovation Clusters will primarily serve as an instrument to help develop existing technological and economical strengths. Therefore a critical mass of industry, research, and development as well as knowledge, skills, and experience must be available within the region. Based on the theory of economic efficiency [22] another cornerstone of the general strategy of the Fraunhofer Innovation Clusters is to embrace all relevant decision-making bodies in industry, science, education and government in defined regional locations. Therefore a strong financial commitment from the regional industry as well as the regional government in addition to current expenditure is indispensable for setting up a Fraunhofer Innovation Cluster. Being able to mobilize funding from the industry involved is not only a prerequisite for setting up an innovation cluster, but ensures commitment on the part of all those concerned.

Fraunhofer Innovation Clusters are, in the first instance, project clusters rather than communication networks (Figure 1). It is crucial to work together towards a joint objective, which can best be achieved through concrete projects. Projects are needed for new ideas and inventions to bridge the gap between industry and scientific research results. With this project orientation the distribution of tasks within each innovation landscape is maintained. While the public establishments create the basis for new products and services, the funds provided by industry are used to implement and market these innovations. This promotes collaboration in the development of concrete products. However, the public funded projects are restricted to one federal state in Germany due to the fact that regional authorities are responsible for co-financing the initiatives. Thus, the concepts of multidimensional clustering [17] [18] and the global-value-chain-approach are actually not taken into account [16].

The strong focus on a specific technological and benefit-oriented issue, which furthermore pushes a global challenge — such as energy, environment, and health care-assures a high national and international visibility in the relevant communities. Therefore the presence of a Fraunhofer Innovation Cluster is an aspect of regional marketing for the federal states. The concrete working projects within the clusters can generate a critical mass of knowledge, experience, and skills that complement one another. The positive effects of jointly achieved success on further cooperation are invaluable and therefore the completed projects build starting points for further collab-orations. Further effects are the intensified relationships between industry and research within the clusters. At the end of the day joint, harmonized research and development at research institutes, universities and in industry not only provides stimulation and helps to forge links within a cluster, but also has a financial leverage effect.

\section{The Case of the Optics Cluster in Jena}

\subsection{An Industry Cluster since the Nineteenth Century}

Taking Ketels [31] statement "Clusters develop over time; they are not a phenomenon that just appears or disappears overnight" it is worth to take a look at the nineteenth century and the relationships between the three key actors of the optical industry in Germany: Carl Zeiss, Ernst Abbe, Otto Schott, in order to understand the history of the industry cluster in Jena.

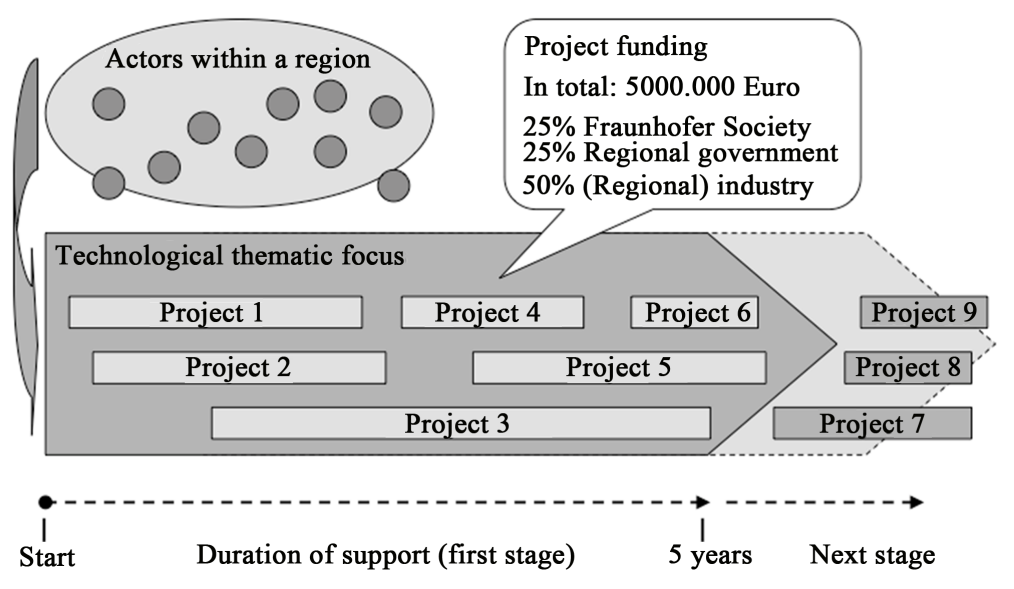

Figure 1. Basic concept of Fraunhofer innovation clusters. 
The Carl Zeiss Jena Company was set up by Carl Zeiss (1816-1888) as an optical workshop in 1846, and at first assembled and sold microscopes from other producers. Soon the workshop designed its own microscopes, but Zeiss realised that while he had the practical skills to build microscopes, he lacked the theoretical insight to develop them further. In 1866, Zeiss approached Ernst Abbe (1844-1905), mathematician and physicist at the local university, and recruited the scientist for his workshop. Later Abbe became the managing director of the Carl Zeiss Company. By hiring scientific staff, Ernst Abbe was a decisive driving force behind integration of R\&D into the company as an important step toward technology leadership. He called for research into glass with enhanced, more constant optical qualities. In 1879 Ernst Abbe came in contact with the Glass researcher Otto Schott (1851-1935), the descendant of an old glassmakers' family in the west of Germany. Carl Zeiss, Ernst Abbe and Otto Schott realised the potential of a close co-operation between them, and set up a private glass laboratory in Jena. In 1884 the Glastechnische Laboratorium Schott (later to become Jenaer Glaswerk Schott) was founded by the three and Carls brother Roderich Zeiss. After only two years, Schott produced its first marketable optical glass. With the improved optical glass an era of immense business expansion began for Car1 Zeiss. In 1889 Ernst Abbe founded the Carl-Zeiss-Stiftung, which today is the sole owner of the Carl Zeiss AG and the Schott AG. In the year 2008 the foundation with its subsidiaries had more than 30.000 employees worldwide and a turnover of 4.9 billion US\$.

In the beginning 21st century Jena stands out of the mass of communities in the eastern part of Germany as a technologically and economically successful region [35]. As the geographical distribution of the patent application shows (Figure 2) Jena - together with Dresden—sticks out as an innovative island with a high number of patent applications and a large quota of small and medium-sized enterprises in its economic structure [36].

Currently in the Jena region, the federal state of Thuringia, 170 companies are active in the field of optics with an annual turnover of more that 2.5 billion US\$ and 14000 employees. In the regional universities and research institutes additionally 900 scientists work on optical technologies. Most of the optics companies in the region are medium-sized companies, only $8 \%$ are large firms with more than 250 employees. However, the firms show an export rate of more than 65\%. Key markets are Europe and North America, but the importance of China and Southeast Asia is increasing.

\subsection{The Current Innovation Network in the Region}

According to Graf and Henning [37] innovative and successful regions have something that could be called a functioning internal system with a sufficient amount of external orientation. The Author analysed the patent activities in a few German innovation regions including the Jena region using patent applications at the German Patent Office where disclosed from 1995 to 2001 in order to map the regional network of innovators [37]. In the seven year period from 1995 to 2001 Jena shows 1776 applications or 253 applications per year. The Author visualised the network graphically by showing the personal relationships of cooperation (Figure 3). In the

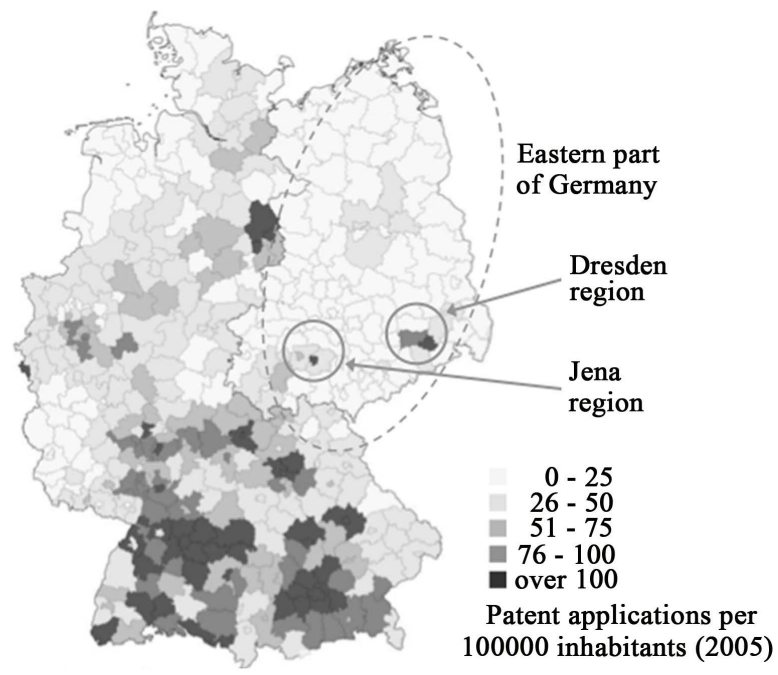

Figure 2. Geographical distribution of patent applications in Germany [36]. 


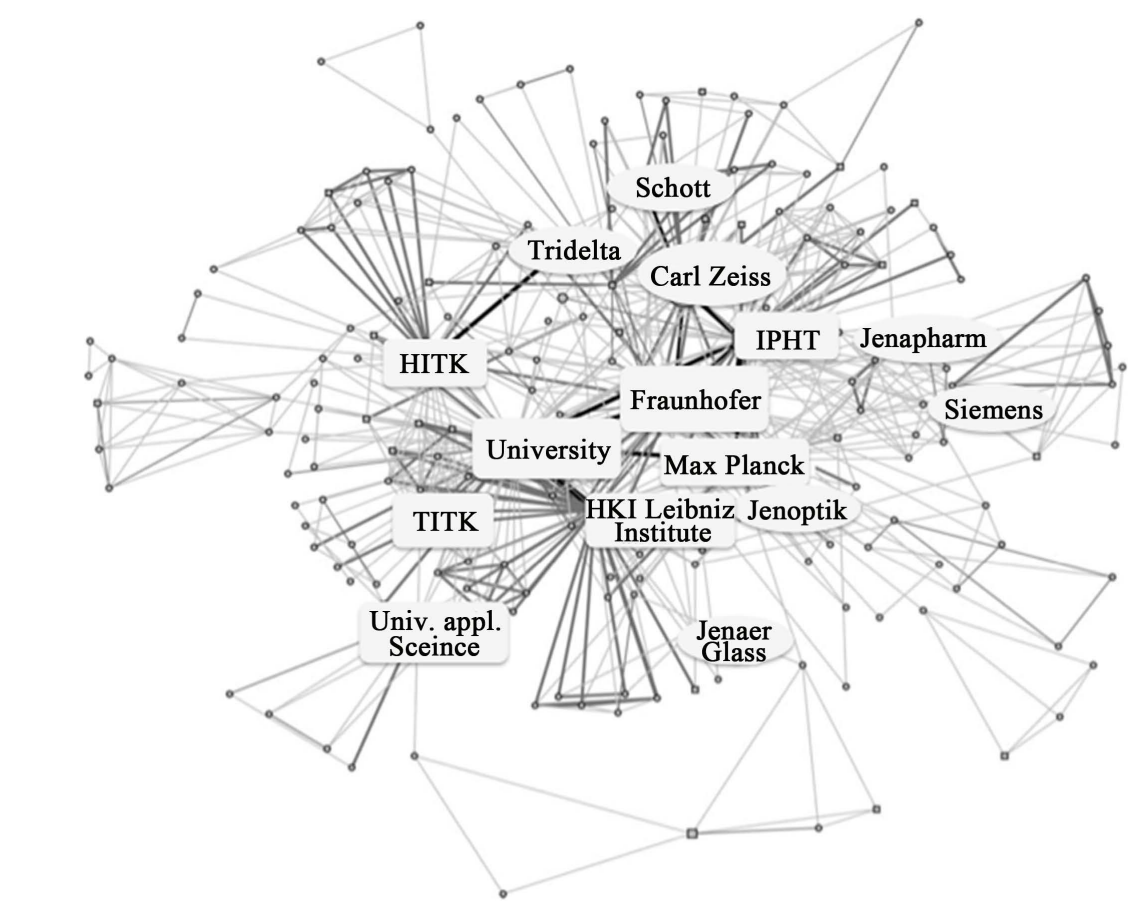

Figure 3. Multipolar network of innovators in Jena [37].

resulting innovator network graphic the main players are represented by a rectangle-in case of a public research organisation - or an ellipse - in case of a private firm. The edges between the nodes represent relationships between the actors. This relationship can be (1) cooperative relationships by joint applicants of same patents (dark-grey) when previous research cooperation can be assumed. The partners can also be related by (2) scientist mobility through joint inventors (light-grey), when the same inventor is named on two separate patents applied for different organisations. In case of (3) both types of relationships the edges are black. The position of knots is produced by multidimensional scaling [38] whereupon more central actors are positioned at the centre of the network. The resultant network of innovators in Jena is clearly multi-polar with a private company-Carl Zeiss - as the most active patentee. The other central actors of the network are both companies as well as university and non-university research institutions. Especially the University is strongly connected to other players by cooperative relationships and by scientists-mobility relationships. The private companies such as Carl Zeiss, Jenoptik, Jenapharm, and Schott are visible actors and tightly connected within the network. The same holds for other non-university research institutes.

Compared to other networks of innovators the Jena case shows two characteristics, which represent an eminent groundwork for the success of today's cluster policy. First of all, the network shows a clear multipolarity with dense linkages between all the central actors and no pronounced predominance of one single innovator. And second, the network shows no separated subnets. Therefore the picture supports the assumption that Jena's leading position in terms of patent efficiency might be the result of intense knowledge flows within the region's network of innovators.

Since 1999, a large part of the companies are organised within an association called OptoNet. Currently OptoNet represents the interests of about 90 companies, research and educational organizations, investment companies as well as public institutions in the field of optical technology. OptoNet is financed by membership fees as well as funding from the German Federal Ministry of Education and Research and the regional government. The cluster organization OptoNet not only promotes the networking of its members and partners but also defines topics for a purpose-oriented cooperation. Optical technologies are on one hand an application market (eyeglasses, consumer optics, sensors) and on the other hand an enabling technology for different industries and markets such as medical technology, automotive, consumer electronics, photovoltaic, lighting, and manufacturing. OpoNet's cluster orientation is therefore widely diversified, intersectoral, and technology-driven. The focus on technology is complemented by numerous cooperative relationships to other networks and industrial societies. 


\subsection{The Fraunhofer Innovation Cluster in Jena}

In order to maintain the leading position in the optics industry, the regional research partners, and industry players have got together to build on these intense relationships and to deepen them by a new cluster initiative. Objective target of the entire cluster initiative is to develop existing technological foundations by the hand of strategic projects in order to strengthen the competitive position of the relevant players in the region. The aim was to form an innovation cluster based on concrete development projects with a thematic focus (Optical systems for digital information storage and reproduction for mass markets). Motivation of the development projects is to produce, for instance, miniature digital projectors for universal applications, micro-optical sensors inspired by biological models, and non-contact 3D-measuring systems. Driving force behind this cluster initiative is the Fraunhofer Society as one of the leading research partners in the cluster. Other relevant research organisations in the region are included in the cluster, for example the Friedrich-Schiller-University Jena, the University of Applied Science (technical college) in Jena, and the Technical University in Ilmenau, a city about $50 \mathrm{~km}$ off.

In a process of coordination the Fraunhofer Society, the regional Government and the leading industry partners (large enterprises as well as small and medium sized firms) have formulated a basic cluster strategy and some fundamental development orientations regarding the thematic focus. Furthermore, in these negotiations the federal state government of Thuringia agreed to support the cluster projects with 3 Million US\$ and the regional optics industry agreed to bring in another to 6 Million US\$ in the next four years. This is a visible expression of the financial commitment from the cluster actors. With regard to the basic strategy the cluster actors agreed on three technology platforms projects as well as three superior flagship projects. Aim of the technology platform projects (e.g. micro- and nanostructures, packaging and joining techniques, ultra-precision machining) is to expand the leading position in research in order to build the base for projects with a large number of partners. The flagship projects are in line with relevant application markets (bio-inspired microoptics, digital projection, measuring and quality control) in order to strengthen national and international visibility. In this way more than 20 platform project and application projects have been accomplished since 2006, which are of vital importance for the strategic development of the Jena optics region. All projects can be seen as catalysers for follow-up projects. Regarding the research institutes and universities the projects have been valuable in order to align the research focus with the needs of the industrial partners in the region. By one hand it came to a homogenisation of research topics, by the other hand to an exploitation of new application markets.

Competitive advantages of the Jena optics cluster are the regional and local concentration of highly skilled labour as well as the strong network ties between key players in the sector. Table 2 shows an assessment of the

Table 2. Assessment of the Jena optics cluster.

\begin{tabular}{|c|c|c|}
\hline Cluster explanation & Assessment & Description \\
\hline $\begin{array}{l}\text { Positive External effect, } \\
\text { competitive position }\end{array}$ & $* * *$ & $\begin{array}{l}\text { “Jena” and 'Carl Zeiss' as well established brands, strong } \\
\text { competitive position under the top three of German optics locations }\end{array}$ \\
\hline Highly skilled labour & $* * * * *$ & $\begin{array}{l}2 \text { Universities and many research institutes in the city, } \\
\text { additional universities in the state }\end{array}$ \\
\hline $\begin{array}{l}\text { Specialized subcontractors, } \\
\text { distinct cluster depth }\end{array}$ & $* * * *$ & $\begin{array}{l}\text { Whole value chain of optical products in the region, } \\
\text { high range of vertically related industries in the cluster, } \\
\text { more or less complete supply chains }\end{array}$ \\
\hline Rapid flows of knowledge & $* * *$ & Knowledge exchange through workshops and cluster meetings \\
\hline Strong network ties & $* * * * *$ & $\begin{array}{l}\text { Strong and long standing relationships } \\
\text { between the key actors in the region }\end{array}$ \\
\hline Cluster activity & $* * * *$ & $\begin{array}{l}\text { Activity-rich cluster which tends to conduct the strategy-setting, } \\
\text { product development, and marketing within the region }\end{array}$ \\
\hline Openness to new network & ** & $\begin{array}{l}\text { Inward looking and self-reflecting cluster, } \\
\text { which is not very open to other networks }\end{array}$ \\
\hline Knowledge creation and transfer & $* * *$ & $\begin{array}{l}\text { Good knowledge transfer from research to industry, } \\
\text { competition hinders open forms of knowledge creation }\end{array}$ \\
\hline Geographic scope & $* * *$ & $\begin{array}{l}\text { Small geographic scope (within one federal state) } \\
\text { with some considerable exceptions }\end{array}$ \\
\hline Growth potential & $* * * *$ & High growth potential of optics and photonics industry \\
\hline $\begin{array}{l}\text { Technological focus } \\
\text { and diversified markets }\end{array}$ & $* * * *$ & $\begin{array}{l}\text { Narrow cluster in terms of technology but relatively } \\
\text { broad cluster in terms of applications (markets) }\end{array}$ \\
\hline
\end{tabular}


theoretical cluster explanations according to theoretical considerations [23] [24] [27]. Taking Enrights [29] cluster differentiation, the Jena optics cluster can certainly be considered as a 'working cluster'. The cluster is composed of a large number of connected companies, which understand their interdependence trying to get a competitive advantage out of it. Knowledge about each other and mutual trust have developed over the last 25 years.

The Fraunhofer Innovation Cluster in Jena is an essential element in a continued cluster development strategy. Recently the EU commissioner for regional development declared the Jena optics region to be outstandingly positioned in the international competition and a model for improving the profiles of European Union regions. With this vote of confidence, cooperative projects between research institutions in the region and companies were awarded funding over 35 Million US\$ to 2013 through programs from the European Union, the federal and regional government. All projects are coordinated by a private limited company (CoOPTICS Ltd.), subsidiary of the OptoNet cluster organisation. Strategic goal is the transfer of top technological achievements in innovation for the growth markets environment, energy, safety, mobility life science, and medicine. Currently the cluster members have set themselves the goal of establishing "Green Photonics" as a strategic field in the State of Thuringia and to establish a new Fraunhofer Innovation Cluster. The term "Green Photonics" brings together the various application possibilities of light for protecting the environment, save energy, reduce greenhouse gases, and contribute to environmentally sustainable production.

\section{Summary and Conclusion}

Universities, colleges and other research institutions may be important actors of regional networks and industrial agglomerations, especially in those clusters which have a pronounced technology-orientation. The Fraunhofer Society in Germany is suchlike a regional innovation partner and mostly located in well-developed areas with industrial firms, universities and higher education institutes nearby. Fraunhofer Society promotes innovation clusters to intensify the existing forms of networking and to strengthen the competitive position by more efficiently tapping existing potential. Innovation clusters provide impetus for the further development of regional centres of excellence, and primarily serve as instruments to develop existing strengths.

As a case study, the Jena optics cluster shows a high geographic concentration of interconnected firms, suppliers, service providers, and research institutions in the field of optics. The existing structures of knowledge exchange have developed over a long time based on preliminary works, which range till the time after the German reunification and with roots going back to three outstanding personalities in the nineteenth century. Long-lasting cooperation may lead to common trust, mutual understanding, and actor-related certainty, which are the groundwork for cooperative innovation.

Another lesson from the Jena case is that a critical mass of industry, research and development as well as knowledge, skills and experience must be available within the region. Moreover, a strong financial commitment from regional industry and regional government in addition to current expenditure is indispensable for setting up a Fraunhofer Innovation Cluster. Being able to mobilize financial involvement ensures high commitment on the part of all those concerned.

Finally, the concept of Fraunhofer Innovation Clusters goes far beyond the support of knowledge exchange and networking. The clusters are firstly project clusters rather than communication networks. Therefore, it is crucial to work together within concrete projects and towards a joint objective. Content-related work tends to result inevitably in network structures. The positive effects of jointly achieved success on further cooperation are invaluable and therefore the project results build initial points for further cooperation. Successful first-stage projects and joint achievements can be seen as catalysers for follow-up projects. The Jena case also shows that a common vision, a joint strategic process, and mutually addressed market applications create an invisible link across the different cluster actors.

\section{References}

[1] Eisingerich, A.B., Bell, S.J. and Tracey P. (2010) How Can Clusters Sustain Performance? The Role of Network Strength, Network Openness, and Environmental Uncertainty. Research Policy, 39, 239-253. http://dx.doi.org/10.1016/j.respol.2009.12.007

[2] Delgado, M., Porter, M.E. and Stern, S. (2010) Clusters and Entrepreneurship. Journal of Economic Geography, 10, 495-518. http://dx.doi.org/10.1093/jeg/lbq010 
[3] Ingstrup, M.B. and Gamgaard, T. (2013) Cluster Facilitation from a Cluster Life Cycle Perspective. European Planning Studies, 21, 556-574. http://dx.doi.org/10.1080/09654313.2012.722953

[4] Andreassen, L.E., Coriat, B., den Hertog, F. and Kaplinsky, R. (1995) Conclusions. In: Andreassen, L.E., Coriat, B., den Hertog, F. and Kaplinsky, R., Eds., Europe’s Next Step. Organisational Innovation, Competition and Employment, Frank Cass, Essex and Portland, 321-332.

[5] Malecki, M.J. (1991) Technology and Economic Development: The Dynamics of Local, Regional, and National Change. Longman, Essex.

[6] Tödtling, F. (1994) The Uneven Landscape of Innovation Poles: Local Embeddedness and Global Networks. In: Amin, A. and Thrift, N., Eds., Globalization, Institutions, and Regional Development in Europe, Oxford University Press, Oxford, 68-90.

[7] Lundvall, B.-A. and Johnson, B. (1995) The Learning Economy. Journal of Industry Studies, 1, $23-42$. http://dx.doi.org/10.1080/13662719400000002

[8] Tracey, P., Heide, J.B. and Bell, S.J. (2014) Bringing "Place” Back in Regional Clusters, Project Governance, and New Product Outcomes. Journal of Marketing, 78, 1-16. http://dx.doi.org/10.1509/jm.13.0524

[9] Maillat, D. (1995) Territorial Dynamic, Innovative Milieus and Regional Policy. Entrepreneurship \& Regional Development, 7, 157-165. http://dx.doi.org/10.1080/08985629500000010

[10] St. John, C. and Pouder, R.W. (2006) Technology Clusters versus Industry Clusters: Resources, Networks, and Regional Advantages. Growth and Change, 37, 141-171. http://dx.doi.org/10.1111/j.1468-2257.2006.00313.x

[11] Porter, M.E. (2000) Location, Competition and Economic Development: Local Clusters in a Global Economy. Economic Development Quarterly, 14, 15-34. http://dx.doi.org/10.1177/089124240001400105

[12] Marshall, A. (1920) Principles of Economics. 8th Edition, Macmillan, London.

[13] Krugman, P. (1991) Geography and Trade. MIT Press, Cambridge, MA.

[14] Porter, M.E. (1990) The Competitive Advantage of Nations. Free Press, New York.

[15] Porter, M.E. (1998) Clusters and New Economics of Competition. Harvard Business Review, 76, 77-90.

[16] Gertler, M.S. and Levitte, Y.M. (2005) Local Nodes in Global Networks: The Geography of Knowledge Flows in Biotechnology Innovation. Industry and Innovation, 12, 487-507. http://dx.doi.org/10.1080/13662710500361981

[17] Bathelt, H. (2004) Toward a Multidimensional Conception of Clusters: The Case of the Leipzig Media Industry, Germany. In: Power, D. and Scott, A.J., Eds., Cultural Industries and the Production of Culture, Routledge, London, 147-168.

[18] Wang, J. and Mei, L. (2009) Dynamics of Labour-Intensive Clusters in China: Relying on Low Labour Costs or Cultivating Innovation? International Institute for Labor Studies, Geneva, Discussion Paper 195.

[19] Isaksen, A. (2005) Regional Cluster Building on Local and Non-Local Relationships. A European Comparison. In: Lagendijk, A. and Oinas, P., Eds., Proximity, Distance and Diversity. Issues on Economic Interaction and Local Development, Ashgate, Aldershot, 129-151.

[20] Bathelt, H., Malmberg, A. and Maskell, P. (2004) Clusters and Knowledge: Local Buzz, Global Pipelines and the Process of Knowledge Creation. Progress in Human Geography, 28, 31-56.

[21] Evers, H.D. (2008) Knowledge Hubs and Knowledge Clusters: Designing a Knowledge Architecture for Development. Center for Development Research (ZEF), University of Bonn, Bonn.

[22] Aharonson, B.S., Baum, J.A. and Feldman, M.P. (2007) Desperately Seeking Spillovers? Increasing Returns, Industrial Organization and the Location of New Entrants in Geographic and Technological Space. Industrial and Corporate Change, 16, 89-130. http://dx.doi.org/10.1093/icc/dtl034

[23] Feldman, M.P. (2000) Location and Innovation: The New Economic Geography of Innovation, Spillovers, and Agglomeration. In: Clark, G.L., Feldman, M.P. and Gertler, M.S., Eds., The Oxford Handbook of Economic Geography, Oxford University Press, Oxford, 373-394.

[24] Granovetter, M.S. (1985) Economic Action and Social Structure: The Problem of Embeddedness. American Journal of Sociology, 91, 481-510. http://dx.doi.org/10.1086/228311

[25] Rugman, A.M. and D’Cruz, J.R. (2002) Multinationals as Flagship Firms: Regional Business Networks. Management International Review, 42, 347-352.

[26] Saxenian, A.L. (1994) Regional Advantage. Harvard University Press, Cambridge, MA.

[27] Tallman, S. and Phene, A. (2007) Leveraging Knowledge across Geographic Boundaries. Organization Science, 18, 252-260. http://dx.doi.org/10.1287/orsc.1060.0227

[28] Lawson, C. and Lorenz, E. (1999) Collective Learning, Tacit Knowledge and Regional Innovative Capacity. Regional 
Studies, 33, 305-317. http://dx.doi.org/10.1080/713693555

[29] Enright, M.J. (2003) Regional Clusters: What We Know and What We Should Know. In: Bröcker, J., Dohse, D. and Soltwedel, R., Eds., Innovation Clusters and Interregional Competition, Springer, Berlin, 99-129. http://dx.doi.org/10.1007/978-3-540-24760-9_6

[30] Whittam, G. and Danson, M. (2001) Power and the Spirit of Clustering. European Planning Studies, 9, 949-963. http://dx.doi.org/10.1080/09654310120093287

[31] Ketels, C. (2003) The Development of the Cluster Concept—Present Experiences and further Developments. Paper prepared for the NRW Conference on Clusters, Duisburg, Germany.

[32] Rosenfeld, S.A. (1996) Industrial Strength Strategies: Regional Business Clusters and Public Policy. Aspen Institute Rural Economic Policy Program, Best Practices Series, Industrial Strength Strategies.

[33] Menzel, M.-P. and Fornahl, D. (2009) Cluster Life Cycles-Dimensions and Rationales of Cluster Evolution. Industrial and Corporate Change, 19, 205-238. http://dx.doi.org/10.1093/icc/dtp036

[34] Owen-Smith, J. and Powell, W. (2004) Knowledge Networks as Channels and Conduits: The Effects of Spillovers in the Boston Biotechnology Community. Organization Science, 15, 5-21. http://dx.doi.org/10.1287/orsc.1030.0054

[35] Cantner, U., Helm, R. and Meckl, R. (2003) Strukturen und Strategien in einem Innovationssystem: Das Beispiel Jena. Wissenschaft \& Praxis, Sternenfels.

[36] Eich-Born, M. (2010) Herausforderungenals Chance begreifen, Zum Ausbau von Zukunftsfeldern in den neuen Ländern. In: Vogel, B., Ed., Standort: Neue Länder. Politik-Innovation-Finanzen, Sankt Augustin/Berlin, Germany.

[37] Graf, H. and Henning, T. (2009) Public Research in Regional Networks of Innovators: A Comparative Study of Four East-German Regions. Regional Studies, 43, 1349-1368. http://dx.doi.org/10.1080/00343400802251460

[38] Borgatti, S., Everett, M. and L. Freeman (2002) Ucinet for Windows: Software for Social Network Analysis, Analytic Technologies. Analytic Technologies, Harvard. 